\title{
Diagnostic Value of Platelet Indices in Patients with Pulmonary Embolism
}

\author{
Andi Handayani Tanra ${ }^{1}$, Lopa $\mathrm{AT}^{1,2}$, Esa $\mathrm{T}^{1,3}$, Rauf $\mathrm{DE}^{1,4}$ \\ ${ }^{1}$ Department of Clinical Pathology, Faculty Medicine, Hasanuddin University/Dr.Wahidin Sudirohusodo Hospital, Makassar, Indonesia. \\ E-mail: andihanda23@gmail.com \\ ${ }^{2}$ Tadjuddin Chalid General Hospital, Makassar, Indonesia \\ ${ }^{3}$ Dadi General Hospital, Province of South Sulawesi, Indonesia \\ ${ }^{4}$ Faisal Islamic Hospital, Makassar, Indonesia
}

\begin{abstract}
Pulmonary embolism is caused by a thrombus that blocks the pulmonary artery. The role of the platelet is mainly related to the formation of thrombus. This study aimed to determine the diagnostic value of platelet indices in patients with pulmonary embolism. This study was a retrospective observational research involving 55 patients with and without pulmonary embolism at the period of January 2014 and June 2019 at Dr. Wahidin Sudirohusodo Central Hospital, Makassar. The diagnosis of pulmonary embolism was based on CT angiography. Platelet Indices (PI), Mean Platelet Volume (MPV), Platelet Distribution Width (PDW), and plateletcrit (Pct) were analyzed respectively in two groups. Thirty-one (56.3\%) patients were diagnosed with pulmonary embolism. There was significant difference of MPV and Pct values between embolism and non-embolism group $(9.3 \pm 1.5 \mathrm{fL}$ vs. $9.5 \pm 0.7 \mathrm{fL}, \mathrm{p}=0.49)$ and $(0.2 \pm 0.1 \% \mathrm{vs} .0 .2 \pm 0.1 \%$, $p=0.82)$. Contrastingly, there was a significant difference in PDW value between the two groups (13.2 $\pm 4.9 \mathrm{fL} \mathrm{vs.} 9.9 \pm 1.1 \mathrm{fL}, \mathrm{p}=0.002)$. Receiver Operating Characteristics (ROC) analysis showed cut-off value $\geq 10.5 \mathrm{fL}$ of PDW with a sensitivity of $77.4 \%$, a specificity of $75 \%$, Positive Predictive Value (PPV) of $80 \%$, and Negative Predictive Value (NPV) of $72 \%$. Platelet indices (PDW) showed a good diagnostic value on pulmonary embolism disease with a cut-off value $\geq 0$ of $10.5 \mathrm{fL}$.
\end{abstract}

Keywords: Pulmonary embolism, platelet indices

\section{INTRODUCTION}

Pulmonary embolism is a third cardiovascular emergency following acute myocardial infarction and Cerebrovascular Accident (CVA) to increase mortality and morbidity and cause fatal cases if not immediately treated. A pulmonary embolism is an event of pulmonary tissue infarction due to partial or total blockage of the pulmonary artery caused by a detached thrombus. Approximately $90 \%$ of embolism originates from deep vein thrombosis or pelvic vein thrombosis, which can migrate into the pulmonary circulation. Symptoms and signs depend on occlusion in the pulmonary arteries ranging from asymptomatic to life-threatening conditions, such as hypotension, cardiogenic shock, to sudden cardiac arrest. $^{1-3}$

It is found that the annual incidence of pulmonary embolism resulting in death is 100,000-200,000 cases, while the mortality rate for undiagnosed patients is approximately $30 \%$. If pulmonary embolism is early diagnosed and adequately treated, this mortality rate can fall below $10 \%$. Pulmonary embolism is more common in males than females, with the most common symptoms are shortness of breath (73\%), which usually occurs within seconds, at rest or with activity, pleuritic pain (44\%), and only $24 \%$ of patients have tachycardia. ${ }^{4,5}$

The interaction of platelets against the vessel wall and its role in thrombus formation is significant in the vascular disease's etiology and pathogenesis, including pulmonary embolism, development of thrombosis induced by venostasis hypercoagulability, and vessel wall trauma. Platelet activation plays a vital role in thrombosis, inflammatory processes, and cardiovascular disorders. Larger platelets contain solid granules that are metabolically and enzymatically more active than smaller platelets. Large platelets produce more prothrombotic substances such as thromboxane $A 2$, serotonin, b-thrombomodulin, p-selectin, glycoprotein IIIa, and proinflammatory mediators, including interleukin (IL)-1, IL-3, and IL-6. The substances stimulate megakaryocyte proliferation, which increases the number of platelets. Therefore, large platelets are more susceptible to adhesion and 
aggregation than normal and small platelets. ${ }^{3-8}$

The diagnosis of pulmonary embolism is more complicated than its treatment and prevention. Assessment of clinical features, laboratory tests, additional tests such as chest X-ray, ventilation-perfusion scanning, magnetic resonance angiography, and Computed Tomography (CT) thoracic angiography with contrast as the gold standard for diagnosis of pulmonary embolism is relatively expensive, not available 24 hours at the hospital, and limited to only a few hospitals. ${ }^{5-7}$ Research that discusses the role of biomarkers such as D-dimers, Brain Natriuretic Peptide (BNP), and troponin to assist diagnosis and make prognosis in pulmonary embolism patients has been widely discussed. However, these biomarkers cannot be used as a basis for diagnosis; therefore, it is necessary to seek other ideal, accurate, safe, widely available, and inexpensive laboratory parameters as an alternative. $^{9,10}$

Mean platelet volume, PDW, Pct are indices of platelets that are highly easy to perform on routine blood tests. Mean platelet volume is a measure of the mean platelet count in the blood and represent platelet activation. Platelet distribution width is the degree of heterogeneity in platelet size. Mean platelet volume, plateletcrit, and total platelet count can be used to indicate the number of platelets circulating in the blood. ${ }^{3-5}$

Research by Gunay et al. reported that the MPV, PDW, and platelet values were higher in pulmonary embolism patients than in the control group. ${ }^{2}$ A study by Talay et al. said the MPV cut-off value in pulmonary embolism patients was $8.55 \mathrm{fL}$ with a sensitivity of $82.2 \%$ and a specificity of $52.3 \%{ }^{5}$ Research by Huang et al. reported that PDW and MPV values were higher in pulmonary embolism patients than in the control group with a $p$-value $<0.001$. The cut-off value of MPV was $8.45 \mathrm{fL}$ with a sensitivity of $88.7 \%$, a $50.0 \%$ specificity, Positive Predictive Value (PPV) of 61.9\%, and Negative Predictive Value (NPV) of $78.7 \%{ }^{6}$

There was no study in Indonesia to determine the platelet index's diagnostic value in pulmonary embolism patients. Therefore, based on the description, the authors aimed to use the platelet index in pulmonary embolism patients to determine its diagnostic value as a biomarker to help diagnose pulmonary embolism.

\section{METHODS}

This study was a retrospective observational research conducted by taking secondary data of patients suspected of pulmonary embolism based on the medical records of Dr. Wahidin Sudirohusodo Hospital, Makassar, from January 2014 to June 2019.

The population in this study was patients with pulmonary embolism diagnosed by pulmonary specialists based on CT-scan angiography. Data were obtained and selected from the patient medical record. This study's samples were all accessible population with complete data of the platelet index parameters such as MPV, PDW, and Pct. Exclusion criteria were patients with hematologic malignancies, chronic infections, patients with liver and kidney disorders, and patients with incomplete data of the platelet index parameters such as MPV, PDW, Pct, and CT-radiological data. Angiographic scan of medical records.

The platelet index test was carried out using a hematology analyzer. Research approval was obtained from the Health Research Ethics Committee, Faculty of Medicine, Hasanuddin University/Dr. Wahidin Sudirohusoso Central Hospital. Descriptive statistics, categorical variables will be reported as numbers and percentages, while numerical variables will be reported as mean \pm Standard Deviation (SD). An independent T-test will be used to compare two independent groups. The area under the ROC curve (AUC) was used to determine the platelet index's diagnostic role. A cut-off value was selected to assess sensitivity, specificity, PPV, and NPV. All results were reported by using 95\% confidence intervals (95\% CI). A p-value $<0.05$ was significant.

Research permission was obtained from the Health Research Ethics Committee of the Faculty of Medicine, Hasanuddin University/Dr. Wahidin Sudirohusodo, Makassar, with number 569/UN4.6.4.5.31/PP36/2019.

\section{RESULTS AND DISCUSSIONS}

A total of 55 pulmonary embolic patients with angiographic CT scan results were involved in this study (31 patients in the embolic group and 24 patients in the non-embolic group). The mean age of pulmonary embolism patients involved in this study was $53.1 \pm 17.5$ y.o. The clinical characteristics of the patients were shown in Table 1.

There was no significant difference in MPV values between both groups. Mean MPV values in embolic and non-embolic groups were $9.3 \pm 1.5 \mathrm{fL}$ and $9.5 \pm 0.7 \mathrm{fL}$, respectively $(p=0.49)$. Similar results were also found in other platelet indexes, such as Pct with a mean of $0.2 \pm 0.1 \%$ and $0.2 \pm 0.1 \%$ in embolic and non-embolic groups, respectively $(p=0.82)$. 
Also, the mean PDW value in the embolic group was significantly higher $(13.2 \pm 4.9 \mathrm{fL})$ than the non-embolic group $(9.9 \pm 1.1 \mathrm{fL})$.

Based on the ROC analysis, cut-off value $\geq 10.55$ $f L$ for PDW showed sensitivity of $77.4 \%$, specificity of 75\%, PPV 80.0\%, NPV 72.0\%, and AUC 0.840 (95\% CI $0.736-0.944, P<0.001$ ) (Figure 1).

Table 1. Characteristics of patients with embolic and non-embolic pulmonary

\begin{tabular}{lc}
\hline Variable & Results \\
\hline $\begin{array}{l}\text { Embolic pulmonary }(\mathrm{n}=31) \\
\text { Age (mean } \pm \text { SD) years }\end{array}$ & $53.1 \pm 17.5$ \\
$\quad \begin{array}{l}\text { Gender (\%) } \\
\text { Male }\end{array}$ & $17(54.9)$ \\
$\quad$ Female & $14(45.1)$ \\
Non-embolic pulmonary $(\mathrm{n}=24)$ & \\
Age (mean \pm SD) years & $56.9 \pm 8.8$ \\
$\quad \begin{array}{l}\text { Gender (\%) } \\
\text { Male }\end{array}$ & $16(66.7)$ \\
Female & $8(33.3)$ \\
\hline
\end{tabular}

SD: Standard Deviation; MPV: Mean Platelet Volume; PDW: Platelet Distribution Width; Pct: plateletcrit

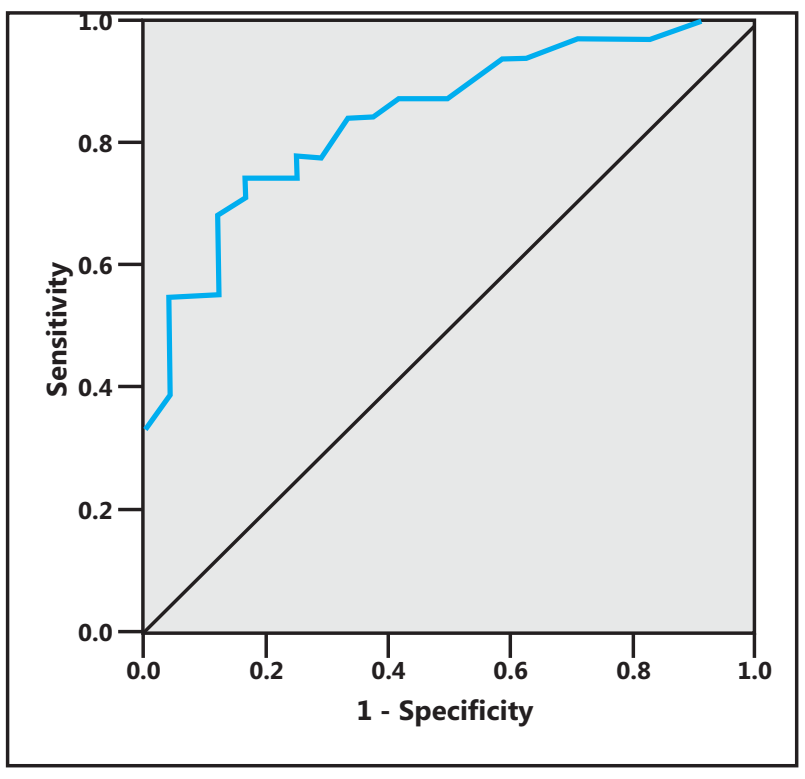

Figure 1. ROC curve of diagnostic value of PDW with AUC 0.840 , cut-off $\geq 10.5 \mathrm{fL}$, the sensitivity of $77.4 \%$, and specificity of $75 \%$

There was no significant difference in MPV between patients with embolic and non-embolic pulmonary in this study. Based on the cut-off value obtained from the Receiver Operating Characteristic (ROC) curve analysis, the PDW had better diagnostic value than the other platelet indices.

Circulating platelets with heterogeneity in size, density, and reactivity have a significant role in the mechanism of thromboembolic disease. Changes in the platelet index, primarily MPV and PDW, indicate platelet activation. Large platelets measured as MPV may represent the mean volume of younger and more reactive platelets and produce more thrombogenic factors. An increase in MPV indicates activation, hyperfunction of the platelets and is associated with a tendency for the thrombotic process. ${ }^{11-13}$

The study conducted by Moharamzadeh et al. showed no significant difference in the platelet index between embolic and non-embolic pulmonary patients. ${ }^{8}$ Research by Varol et al. and Huang et al. found higher MPV in pulmonary embolism patients compared to the control group., ${ }^{3,6}$ Contrastingly study conducted by Hilal et al. and Kostrubiec et al. comparing MPV in pulmonary embolism patients and a control group also showed no significant difference in MPV obtained in both groups. ${ }^{14,15}$

Platelet distribution width reflects the variability of platelets. Research conducted by Cevik et al. showed a statistical significance of PDW value with $p=0.002$. Based on the ROC curve, the cut-off value was $12.8 \mathrm{fL}$, sensitivity was $61 \%$, specificity was $71.64 \%$. However, MPV value was statistically low with $p=0.038$, a cut-off value of $9 \mathrm{fL}, 35 \%$ sensitivity, and $89.5 \%$ specificity. ${ }^{4}$ This was in line with the results in this study that the PDW value was statistically significant with $p=0.002$, but MPV was not statistically significant with $p=0.49$.

Platelet indices have been widely studied because platelet activation causes changes in platelet morphology. During platelet activation, the form of the platelet changes from biconcave to a spherical shape. They will release granules that stimulate the release of prothrombotic factors and are characterized by pseudopods. Pseudopodia are protrusions on the surface of platelets that are formed during platelet activation. This transformation can affect the value of PDW, suggesting a greater specificity, simplicity, and practicality of PDW compared to MPV as a marker to assess platelet activation. ${ }^{11,12}$

The tendency for thrombosis in pulmonary embolism is the result of increased platelet activation and the use of platelets in thrombus formation indicated by an increase in MPV and PDW. The recurrence thrombosis in pulmonary embolism can also be observed from the increase in MPV and PDW. ${ }^{9,10}$ The study conducted by Vagdatli et al. reported that both MPV and PDW were increased in diseases associated with platelet activation, and it was emphasized that PDW is a more specific marker for platelets activation compared to MPV. ${ }^{11}$ 
Table 2. Characteristics of platelet index in patients with embolic and non-embolic

\begin{tabular}{cccc}
\hline Platelet Index & $\begin{array}{c}\text { Embolic Pulmonary } \\
\text { (mean } \pm \text { SD) }\end{array}$ & $\begin{array}{c}\text { Non-embolic Pulmonary } \\
\text { (mean } \pm \text { SD) }\end{array}$ & $\mathbf{P}^{*}$ \\
\hline MPV (fL) & $9.3 \pm 1.5$ & $9.5 \pm 0.7$ & 0.49 \\
PDW (fL) & $13.2 \pm 4.9$ & $9.9 \pm 1.1$ & 0.002 \\
Pct (\%) & $0.2 \pm 0.1$ & $0.2 \pm 0.1$ & 0.82 \\
\hline
\end{tabular}

*Independent T-test; MPV: Mean Platelet Volume; PDW: Platelet Distribution Width; Pct: plateletcrit

Research on the platelet index in patients with pulmonary embolism has been widely carried out abroad with different results. The platelet index is not specific and thus cannot be used as a gold standard. Platelet index is also an indicator of coronary artery disease, stroke, inflammatory disease, kidney and liver disease, type 2 diabetes mellitus, malignancy, and anti-platelet therapy. ${ }^{6,11}$ Besides, some aspects of various detection technologies such as the type and method of the hematology analyzer, the amount and type of anticoagulant, and the time interval between blood collection and sample processing can produce

\section{REFERENCES}

1. Tarbox A, Swaroop M. Pulmonary embolism. International Journal of Critical Illness and Injury Science. 2013. Available from: http://dx.doi.org/ 10.4103/2229-5151.109427. (accessed 12 May, 2019).

2. Wojcik M, Wojcik J, Skoczynskis K. Evaluation of platelet indexes as potential biomarker of suspected pulmonary embolism. European Journal Clinical Exp Medicine. 2019. Available from: http://dx.doi.org/ 10.15584/ejcem.2019.2.1. (accessed 12 May, 2019).

3. Varol E, Icli A, Uysal B, Ozaydin M. Platelet indices in patient with acute pulmonary embolism. Scandinavian Journal of Clinical and Laboratory Investigation. 2011. Available from: http://dx.doi.org/10.3109/ 00365513.2010.5475596. (accessed 28 May, 2019)

4. Cevik I, Narci H, Dundar G, Ayrik C, Babus S. Is there a diagnostic value for the platelet indices patient in pulmonary embolism?. Hong Kong Journal of Emergency Medicine. 2017. Available from: http://dx.doi.org/10.1177/1024907917743489. (accessed 16 May, 2019)

5. Talay F, Ocak T, Alcelik A, Erkuran K, Akkaya A, et al. A new diagnostic marker for acute pulmonary embolism in Emergency Department: Mean platelet volume. Available from: http://ncbi.nlm.hih.gov. (accessed 12 June, 2019)

6. Huang J, Chen Y, Cai Z, Chen P. Diagnostic value of platelet indexes for pulmonary embolism. American Journal of Emergency Medicine. 2015. Available from: http://dx.doi.org/10.1016/j.ajem.2015.02043. (accessed 8 June, 2019)

7. Chung T, Connor D, Joseph J, Emmett L, Mansbetg R, Peters M. Platelet activation in acute pulmonary embolism. Journal of Thrombosis and Hemostasis. 2007. Available from: http://dx.doi.org/10.1111/ irregularities in laboratory results. ${ }^{11}$

\section{CONCLUSIONS AND SUGGESTIONS}

Mean platelet value and PDW platelet indices increase during platelet activation. In this study, PDW had better diagnostic value than other platelet indices and can be used as a marker in pulmonary embolism patients with a PDW cut-off $\geq 10.55 \mathrm{fL}$. It was recommended to perform further research by adding other variables such as comorbidities or risk factors for pulmonary embolism. j.1538-7836.2007.02461.x. (accessed 8 June, 2019).

8. Moharamzadeh P, Rahman F, Foroughifar S, Shahsavarinia K. Reliability of platelet indices for diagnosing pulmonary embolism; a brief report. Advanced Journal of Emergency Medicine. 2019. Available from: http://dx.doi.org/10.22114/ ajem.V0i0.137. (accessed 18 June, 2019).

9. Araz O, Albez FS, Ucar EY, Kerget BY, Imaz N, Akgun M. Predictive value of mean platelet volume for pulmonary embolism recurrence. Lung, 2017; 195(4): 497-502. Available from: http://dx.doi.org/10.1007/ s00408-017-0020-7. (accessed 28 August, 2019).

10. Hamur H, Kalkan K, Duman H, Durakoğlugil ME, Küçüksu Z, Inci $\mathrm{S}$, et al. Plateletcrit and platelet distribution width as independent predictors of coronary artery ectasia. Koşuyolu Hear J, 2016; 19(3): 173-8. Available from: http://dx.doi.org/10.5578/ khj.20979. (accessed 19 August, 2019).

11. Vagdatli E, Gounari E, Lazaridou E, Katsibourlia E, Tsikopoulou F, Labrianou I. Platelet distribution width: A simple, practical and specific marker of activation of coagulation. Hippokratia, 2010; 14(1): 28. Available from: http://www.researchgate.net/publication/ 43248183. (accessed 18 June, 2019).

12. Koupenova M, Clancy L, Corkrey HA, Freedman JE. Circulating platelets as mediators of immunity, inflammation, and thrombosis. Circ Res, 2018; 122(2): 337-51. Available from: http://dx.doi.org/ 0.1161/CIRCRESAHA.117.310795. (accessed 20 August, 2019).

13. Telo S, Kirkil G, Kaman D, Bulmus FG. Does platelet indices play a role in the distinction of pulmonary embolism clinical forms?. J Turgut Ozal Med Cent, 2017; 24(3): 287-91. Available from: http://dx.doi.org/ 
10.5455/jtomc.2017.03.046. (accessed 8 August, 2019).

14. Hilal E, Neslihan Y, Gazi G, Sinan T, Ayfer AZ. Does the mean platelet volume have any importance in patients with acute pulmonary embolism?. Wien Klin Wochenschr, 2013; 125(13-14): 381-5. Available from: http://dx.doi.org/10.1007/s00508-013-0380-9. (accessed 8 August, 2019).

15. Kostrubiec M, Łabyk A, Pedowska-Włoszek J, Hrynkiewicz-Szymańska $A$, Pacho $\mathrm{S}$, et al. Mean platelet volume predicts early death in acute pulmonary embolism. Heart, 2010; 96(6): 460-5. Available from: http://dx.doi.org/10.1136/hrt.2009. 180489. (accessed 19 August, 2019). 